\title{
Synthesis and trypanocidal activity of ent-kaurane glycosides
}

\author{
Ronan Batista, ${ }^{\mathrm{a}, \mathrm{b}}$ Jorge Luiz Humberto, ${ }^{\mathrm{c}}$ Egler Chiari ${ }^{\mathrm{d}}$ and Alaíde Braga de Oliveira ${ }^{\mathrm{b}, *}$ \\ ${ }^{a}$ Departamento de Estudos Básicos e Instrumentais, Universidade Estadual do Sudoeste da Bahia, \\ BR 415, km 03, CEP 45.700-000, Itapetinga, BA, Brazil \\ ${ }^{\mathrm{b}}$ Faculdade de Farmácia, Departamento de Produtos Farmacêuticos, Universidade Federal de Minas Gerais, \\ Av. Antônio Carlos, 6.627, CEP 31.270-901, Belo Horizonte, MG, Brazil \\ ${ }^{\mathrm{c}}$ Instituto de Ciências Exatas e Biológicas, Universidade Federal de Ouro Preto, Morro do Cruzeiro, s/no, \\ Bauxita, 35.400-000, Ouro Preto, MG, Brazil \\ ${ }^{\mathrm{d}}$ Departamento de Parasitologia, Instituto de Ciências Biológicas, Universidade Federal de Minas Gerais, \\ Av. Antônio Carlos, 6.627, CEP 31.270-901, Belo Horizonte, MG, Brazil
}

Received 20 August 2006; revised 21 September 2006; accepted 22 September 2006

Available online 20 October 2006

\begin{abstract}
Novel ent-kaurane glucosides were synthezised by a Koenigs-Knorr reaction between C17 and C19 alcohols derived from kaurenoic acid and 2,3,4,6-tetra- $O$-acetyl-glucopyranosyl bromide, followed by the hydrolysis of the acetates. Main products were assayed in vitro and in vivo against blood trypomastigote forms of Trypanosoma cruzi, the aetiological agent of Chagas' disease (American trypanosomiasis). The results allowed to establish structure-activity relationships among these derivatives, as well as pointed out the C19-methylester-C17-O-glucoside as a potential trypanocidal agent, whose trypanocidal profile was shown to be comparable to those of gentian violet and benznidazole.
\end{abstract}

(c) 2006 Elsevier Ltd. All rights reserved.

\section{Introduction}

Chagas' disease (American trypanosomiasis) belongs to the group of the so-called Drug Neglected Diseases-DND, and is one of the most neglected tropical endemies. ${ }^{1}$ Of the 1223 new drugs (new chemical entities) which entered the market between 1975 and 1996, only two were for Chagas' disease therapy: benznidazole, a nitroimidazole derivative (Rochagan ${ }^{\circledR}$, Roche) and nifurtimox, a nitrofuran derivative (Lampit ${ }^{\circledR}$, Bayer). Both drugs have significant activity in the acute phase, with about $80 \%$ of parasitological cures in treated patients, but their very low antiparasitic effect in chronic patients remains major limitation to their clinical use..$^{1,2}$

Trypanosoma cruzi, a haemoflagelete protozoan (family Trypanosomatidae, order Kinetoplastida), is the aetiological agent of Chagas' disease and its life cycle

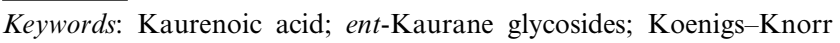
reaction; Trypanosoma cruzi.

* Corresponding author. Tel./fax: +55 $31 \quad 3441$ 5575; e-mail: alaidebraga@terra.com.br involves obligatory passage through vertebrate (mammals, including human) and invertebrate (hematophagus triatomine bugs) hosts. Transmission of the infective trypomastigote form occurs mainly by vector insect bite $(80-90 \%)$, blood transfusion $(5-20 \%)$ and congenital routes $(0.5-8.0 \%)$. The chronic disease is characterized by cardiac, digestive or neurological disturbances. $^{2}$

Control of vectorial and transfusion transmissions has been successfully carried out in Brazil. However, 1620 million people in Latin America are infected with T. cruzi causing 21,000 deaths and 200,000 new infections annually in 15 countries (from Mexico to Argentina). The incidence of this infection afflicts $>80 \%$ of the population in some regions of Bolivia and Mexi$\mathrm{co.}^{3}$ Intense migration of people from endemic Latin American countries must be cause of concern for USA health authorities as it was recorded that between 50,000 and 100,000 people are infected per year in this country. ${ }^{4}$

Gentian violet is recommended for sterilization of blood stored in blood banks of endemic regions, but despite its effectiveness, there are some restrictions to its use due to 
side effects. ${ }^{5}$ New and safer trypanocidal compounds are needed both for prophylaxis and therapy. It is recommended that the search for prophylatic drugs as alternatives to gentian violet must initially involve in vitro assays with trypomastigotes in the presence of blood at $4{ }^{\circ} \mathrm{C}$. Besides being colourless and soluble in the aqueous medium, the compounds should not be inactivated by blood elements or be toxic to them. Many trypanocidal compounds, including available drugs of several therapeutic classes, have been identified, but no one currently can be used as a substitute for gentian violet. ${ }^{2}$ An 8-aminoquinoline compound (WR6026) seems to be the most promising candidate to prevent transfusion associated Chagas' disease. ${ }^{6,7}$

The in vitro assay with $T$. cruzi trypomastigotes could also lead to the identification of potential drugs for Chagas' disease chemotherapy. The in vitro active compounds should be further evaluated for in vivo sensitivity in mice experimentally infected with $T$. cruzi. In a rapid test, the suppressive effect on parasitaemia occurs almost immediately after administration of an effective $\operatorname{drug}^{8}$ and this assay would allow the selection of candidates for curative murine models of acute or chronic Chagas' disease. A limitation to the evaluation of natural products is the amount of sample required for the in vivo assays, about $20 \mathrm{mg}$ for the rapid test (6 h) and $500 \mathrm{mg}$ for a 20-day treatment. Therefore, in vivo assays of natural products are restricted to abundant ones.

Widely occurring and sometimes abundant triterpene and diterpene acids, like ursolic and kaurenoic acids, have been shown to be active in the in vitro assays against the blood trypomastigote form of $T$. cruzi..$^{9-14}$ Kaurenoic acid, a diterpene commonly isolated from some Asteraceae and Annonaceae species, caused not only complete elimination of trypomastigotes from the blood in the in vitro assays at high concentrations $(>1 \mathrm{mM})$, but also complete lysis of erythrocytes ${ }^{11,15}$, although this haemolytic effect had not been reported previously. ${ }^{9}$ Besides, it is insoluble in aqueous medium and cannot be used as a prophylatic agent unless a hydrosoluble derivative could be obtained.
Kaurenoic acid is abundant in some Brazilian plant species belonging to the genera Xylopia (Annonaceae), Mikania and Wedelia (Asteraceae), the highest content being found for $X$. frutescens seeds (ca. 3\%). ${ }^{16}$ It has been used as starting material for chemical synthesis aiming to improve its trypanocidal activity. A series of amides, amines and amine hydrochlorides was obtained by reactions on the carboxyl group. Aqueous solubility of the amine salts did not improve the trypanocidal activity level in relation to kaurenoic acid, although a decrease of haemolysis was observed. ${ }^{15}$

The potentiality of the abundant kaurenoic acid for synthetic modifications is far from being completely exploited. In the present paper, we report the synthesis of glycosides derived from this diterpene acid and their evaluation as trypanocidal agents.

\section{Results and discussion}

\subsection{Chemistry}

Our synthetic approach involved the conversion of kaurenoic acid (1) into the alcohols 3 and $\mathbf{4}$ that were submitted to glycosidation (Scheme 1). The methyl ester $\mathbf{2}$ and the alcohols $\mathbf{3}$ and $\mathbf{4}$ were obtained according to usual procedures: esterification with diazomethane, followed by $\mathrm{LiAlH}_{4}$ reduction (3) ${ }^{15}$ or hydroboration-oxidation (4). The ent-16 $\alpha$ configuration of 4 was unambiguously assigned previously. ${ }^{17}$

Glycosidation of $\mathbf{3}$ by the classic Koenigs-Knorr reaction ${ }^{18,19}$ (Scheme 2) was carried on with 2,3,4,6-tetra$O$-acetyl-glucopyranosyl bromide (5), in the presence of $\mathrm{Hg}(\mathrm{CN})_{2}$, in toluene, at ca. $80^{\circ} \mathrm{C}(80 \mathrm{~h})$, and required a long time $(140 \mathrm{~h})$, affording the alcohol acetate 7 as major product $(50 \%$ isolated yield) and a mixture (1:1) of the peracetylated $\beta$-glycosides $\mathbf{8 a} / \mathbf{b}$ (34\% yield) that, under hydrolysis with sodium methoxide, gave a mixture (1:1) of the $\beta$-glucosides $\mathbf{1 0 a} / \mathbf{b}$ whose separation could not be achieved. The $\beta$-configuration of the anomeric carbons in $\mathbf{8 a} / \mathbf{b}$ and $\mathbf{1 0 a} / \mathbf{b}$ was indicated by the $\mathrm{H}-1^{\prime}$ coupling constants $(\mathbf{8 a} / \mathbf{b}, \delta 4.41, \mathrm{~d}, J=7.8 \mathrm{~Hz} ; \mathbf{1 0 a} / \mathbf{b}, \delta 4.18$,

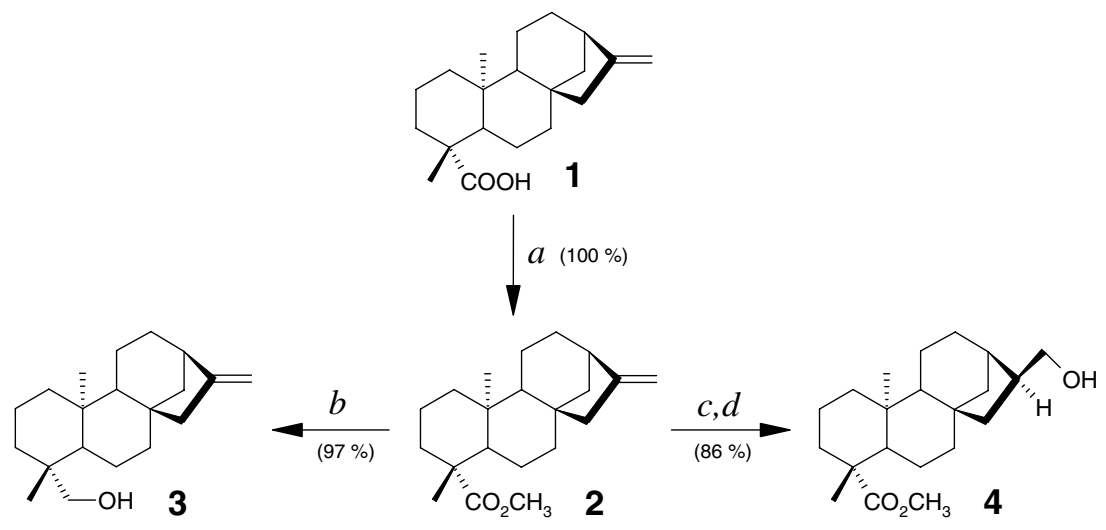

Scheme 1. Synthesis of the kaurane alcohols 3 and 4. Reagents and conditions: (a) $\mathrm{CH}_{2} \mathrm{~N}_{2}, \mathrm{Et}_{2} \mathrm{O}, 4 \mathrm{~h}$; (b) $\mathrm{LiAlH}_{4}, \mathrm{THF}, \mathrm{reflux}, 3 \mathrm{~h}$; (c) $\mathrm{NaBH}$, $\mathrm{BF}_{3} \cdot \mathrm{OEt}_{2}$, THF, $2 \mathrm{~h}$; (d) $\mathrm{NaOH}, \mathrm{H}_{2} \mathrm{O}_{2}, 1 \mathrm{~h}$. 

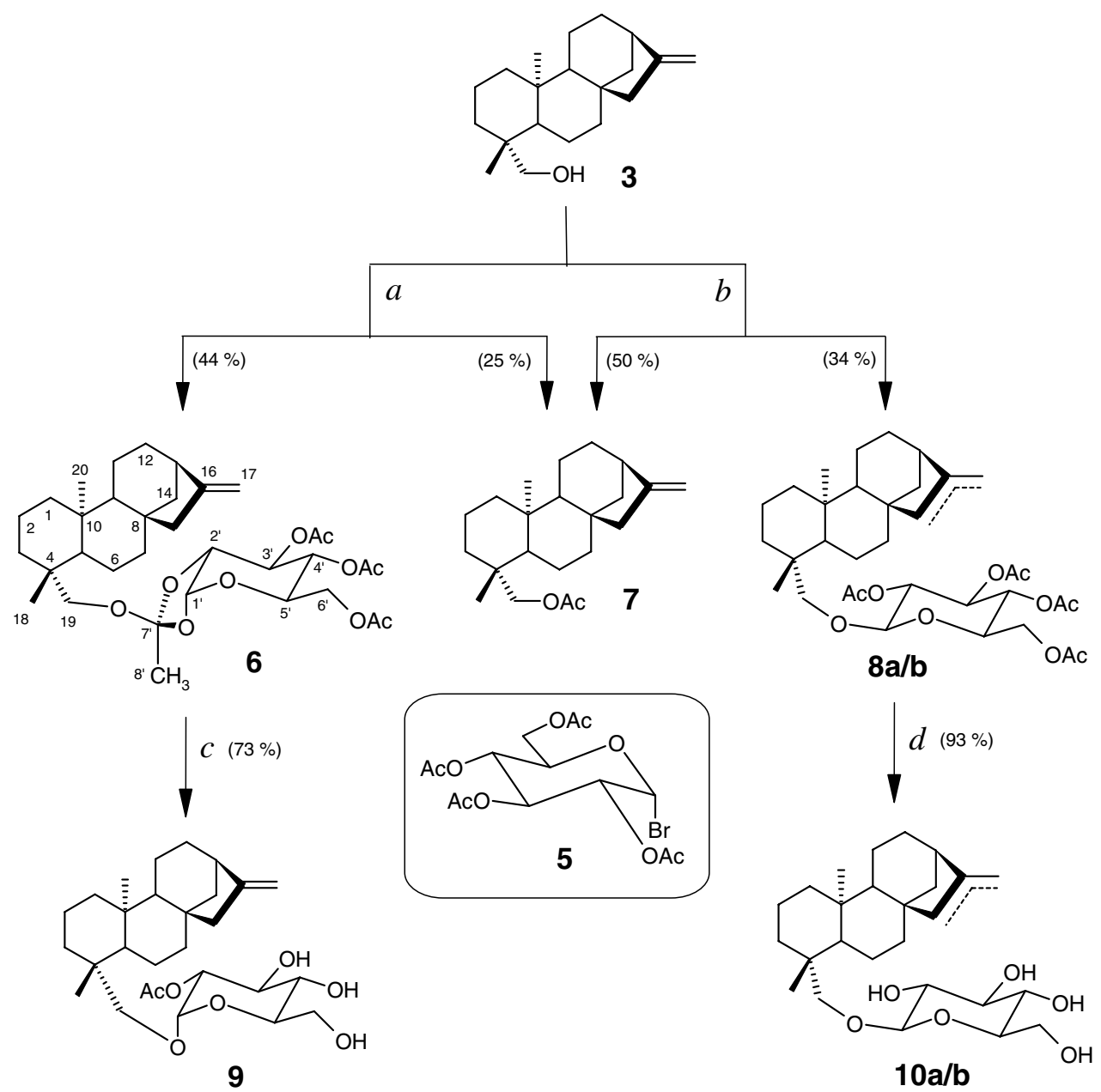

Scheme 2. Synthesis of the kaurane derivatives 6-10a/b from the alcohol 3. (a) $\mathrm{C}_{6} \mathrm{H}_{5} \mathrm{Me},(\mathbf{5}), \mathrm{Hg}(\mathrm{CN})_{2}, \mathrm{rt}(24 \mathrm{~h}), 80^{\circ} \mathrm{C}, 66 \mathrm{~h}$; (b) $\mathrm{C}_{6} \mathrm{H}_{5} \mathrm{Me},(\mathbf{5})$, $\mathrm{Hg}(\mathrm{CN})_{2}, 80^{\circ} \mathrm{C}, 140 \mathrm{~h}$; (c) $\mathrm{MeOH} / \mathrm{H}_{2} \mathrm{O} / \mathrm{Et}_{3} \mathrm{~N}$ (8:1:1), rt, 24 h; (d) $\mathrm{MeO}^{-} \mathrm{Na}^{+}, \mathrm{MeOH}, \mathrm{rt}, 4 \mathrm{~h}$.

$\mathrm{d}, J=7.6 \mathrm{~Hz})$ and signals for $\mathrm{C}-1^{\prime}$ at $\delta 101.7(\mathbf{8 a} / \mathbf{b})$ and $\delta$ $105.2(\mathbf{1 0 a} / \mathbf{b})$.

Glycosidation of 4 (Scheme 3), in similar conditions used for $3\left[\mathrm{Hg}(\mathrm{CN})_{2}\right.$, toluene, $\left.80^{\circ} \mathrm{C}\right]$, gave the $\alpha$-peracetylated glycoside $\mathbf{1 3}$ (37\% yield) and the acetate derivative 14 (25\% yield). The $\alpha$-glucoside 16 was obtained in $81 \%$ yield after hydrolysis of $\mathbf{1 3}$ with sodium methoxide. Reductive de- $O$-acetylation of $\mathbf{1 3}$ with $\mathrm{LiAlH}_{4}$ afforded the $\alpha$-glucoside alcohol $\mathbf{1 5}$ in $68 \%$ isolated yield (Scheme 3). ${ }^{1} \mathrm{H}$ NMR spectra of 13,15 and 16 exhibited a one proton doublet at $\delta 5.08(J=3.7 \mathrm{~Hz}), 4.77$ $(J=3.8 \mathrm{~Hz})$ and $4.77(J=3.8 \mathrm{~Hz})$, respectively, and are consistent with $\alpha$-anomeric glycosides. Characteristic chemical shifts of $\mathrm{C}^{-1}{ }^{\prime}$ anomeric carbons were observed in ${ }^{13} \mathrm{CNMR}$ spectra of $\mathbf{1 3}(\delta 96.2), 15(\delta$ 100.4) and $16(\delta$ 100.4).

Attempts to obtain higher yields in the glycosidation of the alcohols $\mathbf{3}$ and $\mathbf{4}$ were carried on by keeping the Koenigs-Knorr reaction at room temperature for $24 \mathrm{~h}$ and then heating to $80{ }^{\circ} \mathrm{C}$ until the disappearance of the starting materials in TLC. These procedures led to the orthoester $6(44 \%)$ and the alcohol acetate $7(25 \%)$ (Scheme 2), as well as to the orthoester $11(54 \%)$ and the glucoside 12 (37\%) (Scheme 3). Hydrolysis of 6 with $\mathrm{MeOH} / \mathrm{H}_{2} \mathrm{O} / \mathrm{Et}_{3} \mathrm{~N}(8: 1: 1)$ gave the $\alpha$-2- $O$-acetylglucoside $9(73 \%$ yield $){ }^{1} \mathrm{H}$ and ${ }^{13} \mathrm{C}$ NMR spectra showed characteristic signals for $\mathrm{H}-1^{\prime}(\delta 5.66, \mathrm{~d}, J=5.2 \mathrm{~Hz}), \mathrm{C}-1^{\prime}(\delta$ $96.8)$ and ${\mathrm{C}-7^{\prime}}^{\prime}(\delta 121.5)$ of the orthoester 6 , and for the anomeric $\mathrm{H}-1^{\prime}(\delta 6.10, \mathrm{~d}, J=3.6 \mathrm{~Hz})$ and $\mathrm{C}-1^{\prime}(\delta$ 93.6) of 9.

The alcohol acetates $\mathbf{7}$ and $\mathbf{1 4}$ are indicative of the formation of the respective orthoesters what very often occurs in the classic Koenigs-Knorr glycosidation procedure and involves the participation of the carbonyl group at C-2' of the glycosylating agent. Formation of these products is favoured when the acceptor alcohol is sterically hindered ${ }^{20}$ what indeed explains a higher yield of $7(50 \%)$ than $14(25 \%) .{ }^{1} \mathrm{H}$ and ${ }^{13} \mathrm{C}$ NMR data for compounds 1-16 are found in Tables 1 and 2.

\subsection{Trypanocidal activity}

Aiming to evaluate the preliminary trypanocidal activity of the main compounds of this work, in order to select the most potential active ones for the next in vivo assay, an in vitro evaluation of compounds $1-4,9,10 a / b, 15$ and 16 against trypomastigotes of $T$. cruzi (Y strain) 


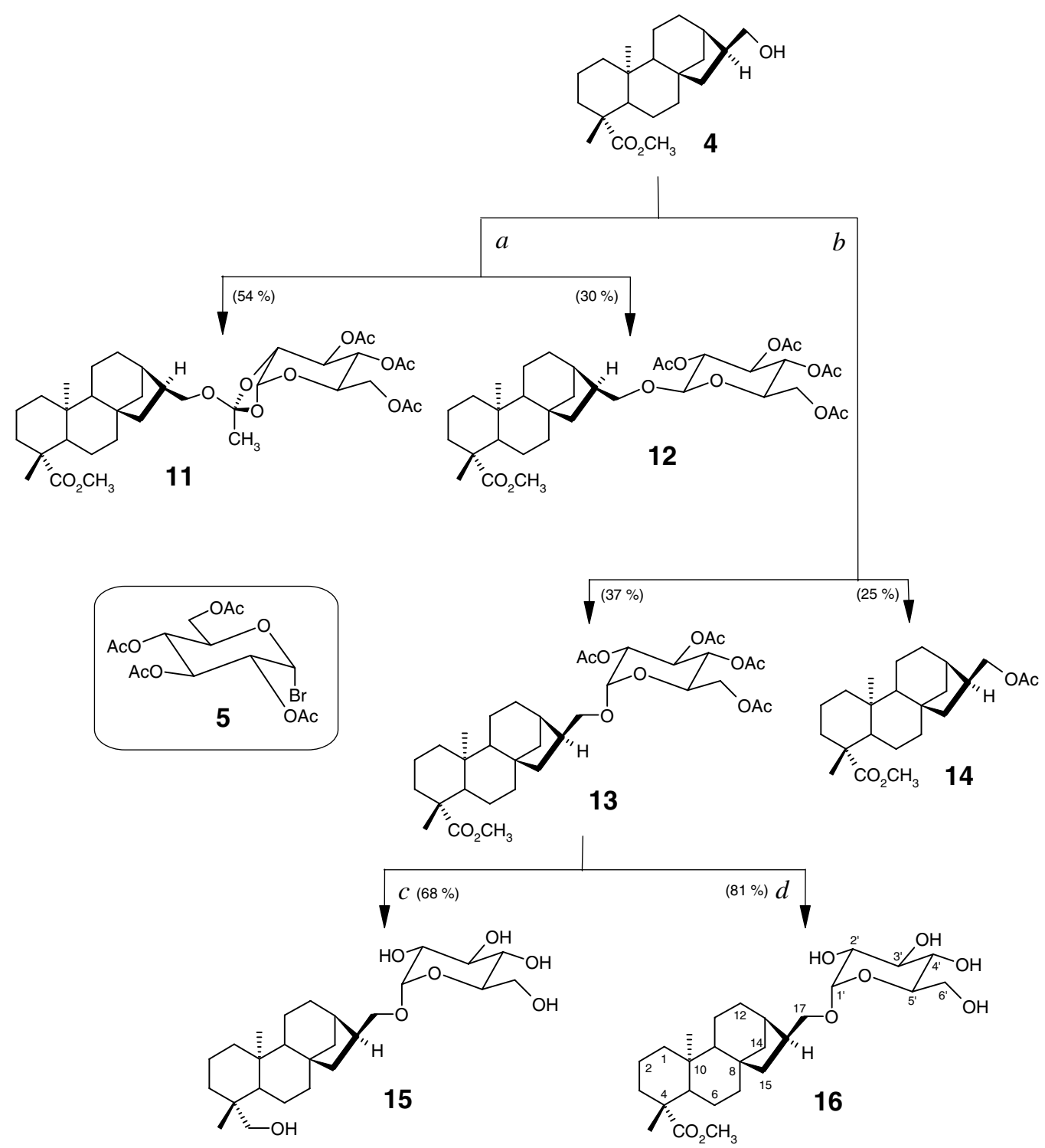

Scheme 3. Synthesis of the kaurane derivatives 11-16 from the alcohol 4. Reagents and conditions: (a) $\mathrm{C}_{6} \mathrm{H}_{5} \mathrm{Me},(\mathbf{5}), \mathrm{Hg}(\mathrm{CN})_{2}, \mathrm{rt} .24 \mathrm{~h}, 60{ }^{\circ} \mathrm{C}, 48 \mathrm{~h}$, $80{ }^{\circ} \mathrm{C}, 24 \mathrm{~h}$; (b) $\mathrm{C}_{6} \mathrm{H}_{5} \mathrm{Me},(5), \mathrm{Hg}(\mathrm{CN})_{2}, 70{ }^{\circ} \mathrm{C}, 72 \mathrm{~h}$; (c) $\mathrm{LiAlH}_{4}, \mathrm{THF}, \mathrm{rt}, 1 \mathrm{~h}$; (d) $\mathrm{MeO}^{-} \mathrm{Na}^{+}, \mathrm{MeOH}, 4 \mathrm{~h}$.

was performed according to methodology previously described, ${ }^{11,17,21,22}$ and the results are shown in Table 3.

Compounds 1, 2 and 4 disclosed the expected profile, causing complete (1 and $\mathbf{4}$ ) or almost complete (2) elimination of parasites, besides lysis of erythrocytes $(\mathbf{1}$ and 4), at concentrations higher than $1 \mathrm{mM}$, the haemolytic effect being stronger (total lysis) for kaurenoic acid (1) than for the methyl ester alcohol derivative 4 (partial lysis) and the methyl ester 2 (absence of lysis). Kaurene alcohol $\mathbf{3}$ was less active, complete elimination of parasites occurring only at $5.00 \mathrm{mM}$ without significant haemolysis. It seems that the haemolytic effect is related to the presence of a carboxylic acid group at C19. For glucosides $\mathbf{9}, \mathbf{1 0 a} / \mathbf{b}$ and $\mathbf{1 5}$, in comparison with the respective aglycones $\mathbf{3}$ and $\mathbf{4}$, a decrease in the trypanocidal effect was observed. On the other hand, the C19methylester-C17-O-glucoside $\mathbf{1 6}$ was more active than kaurenoic acid (1) and the corresponding alcohol 4, with the advantage of causing no significant haemolysis, what is a desirable characteristic for a Chagas' disease chemoprophylatic agent. Other favourable properties of $\mathbf{1 6}$, as a potential trypanocidal agent to be added to transfusional blood, are its colourless and better solubility in aqueous media. Besides, the trypanocidal profile of $\mathbf{1 6}$ is very close to the one observed for gentian violet, the standard chemoprophylatic drug, at least in the conditions of the in vitro assays.

Based on the results depicted in Table 3, and considering the amount of each compound available, compounds 2 (kaurenoic acid methyl ester) and $\mathbf{1 6}$ (C19-methylester$\mathrm{C} 17-O$-glucoside) were assayed to determine the sensitivity of $T$. cruzi in vivo within a short period of time $(6 \mathrm{~h})$. A rapid method detecting activity against trypomastigotes circulating blood forms was used for assessment. This method is based on the fact that T. cruzi blood forms intravenously inoculated into mice persist for some hours in the bloodstream without penetrating the host tissues whereas with active drugs 
Table 1. ${ }^{1} \mathrm{H}$ NMR data $\left[\delta \mathrm{ppm}, J \mathrm{~Hz}, \mathrm{CDCl}_{3}\right]$ data for compounds 1-16

\begin{tabular}{|c|c|c|c|c|c|c|c|c|c|}
\hline $\mathrm{H}$ & 1 & 2 & 3 & 4 & 5 & 6 & 7 & $8 a$ & $\mathbf{8 b}$ \\
\hline 13 & $2.64 \mathrm{br} \mathrm{s}$ & $2.64 \mathrm{br} \mathrm{s}$ & $2.63 \mathrm{br} \mathrm{s}$ & $2.13 \mathrm{br} \mathrm{s}$ & - & $2.64 \mathrm{br} \mathrm{s}$ & $2.64 \mathrm{br} \mathrm{s}$ & $2.64 \mathrm{br} \mathrm{s}$ & $2.32 \mathrm{br} \mathrm{s}$ \\
\hline $15 \mathrm{a} / \mathrm{b}$ & $2.05 \mathrm{~m}$ & $2.05 \mathrm{~m}$ & $2.05 \mathrm{~m}$ & $2.2-0.7 \mathrm{~m}$ & - & $2.04 \mathrm{~m}$ & $2.04 \mathrm{~m}$ & $1.98 \mathrm{~m}$ & $5.04 \mathrm{~s}$ \\
\hline 16 & - & - & - & $2.28 \mathrm{~m}$ & - & - & - & - & - \\
\hline $17 \mathrm{a}$ & $4.79 \mathrm{br} \mathrm{s}$ & $4.79 \mathrm{br} \mathrm{s}$ & $4.79 \mathrm{br} \mathrm{s}$ & $3.70 \mathrm{~d}(6.9)$ & - & $4.79 \mathrm{br} \mathrm{s}$ & $4.79 \mathrm{br} \mathrm{s}$ & $4.79 \mathrm{br} \mathrm{s}$ & $1.69 \mathrm{~d}(1.3)$ \\
\hline 18 & $1.24 \mathrm{~s}$ & $1.17 \mathrm{~s}$ & $0.96 \mathrm{~s}$ & $1.16 \mathrm{~s}$ & - & $0.90 \mathrm{~s}$ & $0.94 \mathrm{~s}$ & $0.89 \mathrm{~s}$ & $0.89 \mathrm{~s}$ \\
\hline $19 \mathrm{a}$ & - & - & $3.74 \mathrm{~d}(10.9)$ & - & - & $3.59 \mathrm{~d}(11.0)$ & $4.22 \mathrm{~d}(11.0)$ & $3.95 \operatorname{td}(3.0 ; 9.3)$ & $3.95 \operatorname{td}(3.0 ; 9.3)$ \\
\hline $19 b$ & - & - & $3.43 \mathrm{~d}(10.9)$ & - & - & $3.20 \mathrm{~d}(11.0)$ & $3.87 \mathrm{~d}(11.0)$ & $3.18 \mathrm{~d}(9.3)$ & $3.18 \mathrm{~d}(9.3)$ \\
\hline 20 & $0.95 \mathrm{~s}$ & $0.83 \mathrm{~s}$ & $1.01 \mathrm{~s}$ & $0.81 \mathrm{~s}$ & - & $1.01 \mathrm{~s}$ & $1.03 \mathrm{~s}$ & $1.01 \mathrm{~s}$ & $1.01 \mathrm{~s}$ \\
\hline 21 & - & $3.64 \mathrm{~s}$ & - & $3.64 \mathrm{~s}$ & - & - & - & - & - \\
\hline $2^{\prime}$ & - & - & - & - & $4.84 \mathrm{dd}(4.0 ; 10.0)$ & $4.30 \mathrm{dd}(3.1 ; 5.1)$ & - & $5.20 \mathrm{t}(9.3)$ & $5.20 \mathrm{t}(9.3)$ \\
\hline $3^{\prime}$ & - & - & - & - & $5.56 \mathrm{t}(9.7)$ & $5.19 \mathrm{t}(2.9)$ & - & $4.96-5.12 \mathrm{~m}$ & $4.96-5.12 \mathrm{~m}$ \\
\hline $4^{\prime}$ & - & - & - & - & $5.16 \mathrm{t}(9.7)$ & $4.90 \mathrm{dd}(2.7 ; 9.5)$ & - & & ] \\
\hline $5^{\prime}$ & - & - & - & - & $4.38-4.25 \mathrm{~m}$ & $3.95 \mathrm{ddd}(3.6 ; 4.5 ; 5.4)$ & - & $3.68 \mathrm{ddd}(2.5 ; 4.8 ; 9.5)$ & $\begin{array}{l}3.68 \mathrm{ddd} \\
(2.5 ; 4.8 ; 9.5)\end{array}$ \\
\hline $6^{\prime} \mathrm{a}$ & - & - & - & - & & $4.21 \mathrm{~s}$ & - & $4.28 \mathrm{dd}(4.9 ; 12.2)$ & $4.28 \mathrm{dd}(4.9 ; 12.2)$ \\
\hline $6^{\prime} \mathrm{b}$ & - & - & - & - & $4.12 \mathrm{dd}(3.4 ; 13.0)$ & $4.20 \mathrm{~d}(1.6)$ & - & $4.12 \mathrm{dd}(2.5 ; 12.1)$ & $4.12 \mathrm{dd}(2.5 ; 12.1)$ \\
\hline $8^{\prime}$ & - & - & - & - & - & $1.70 \mathrm{~s}$ & - & - & - \\
\hline \multirow{2}{*}{$\mathrm{CH}_{3} \mathrm{CO}$} & - & - & - & - & $2.04 \mathrm{~s}$ & $2.09 \mathrm{~s}$ & $2.05 \mathrm{~s}$ & $2.01 \mathrm{~s}$ & $2.01 \mathrm{~s}$ \\
\hline & & & & & $2.06 \mathrm{~s}$ & $2.10 \mathrm{~s}$ & - & $2.03 \mathrm{~s}$ & $2.03 \mathrm{~s}$ \\
\hline H & $9^{\mathrm{a}}$ & $10 a^{a}$ & $10 b^{a}$ & 11 & 12 & 13 & 14 & $15^{\mathrm{a}}$ & $16^{\mathrm{a}}$ \\
\hline 13 & $2.61 \mathrm{br} \mathrm{s}$ & $2.61 \mathrm{br} \mathrm{s}$ & $2.28 \mathrm{br} \mathrm{s}$ & $2.19 \mathrm{~m}$ & $2.16 \mathrm{brd}(13.0)$ & $2.14 \mathrm{~m}$ & $2.15 \mathrm{~m}$ & $2.19 \mathrm{br} \mathrm{s}$ & $2.18 \mathrm{br} \mathrm{s}$ \\
\hline $15 \mathrm{a} / \mathrm{b}$ & $2.04 \mathrm{~m}$ & $2.05 \mathrm{~m}$ & $5.03 \mathrm{~s}$ & $2.2-0.8 \mathrm{~m}$ & $2.1-0.8 \mathrm{~m}$ & $2.1-0.7 \mathrm{~m}$ & $2.2-0.7 \mathrm{~m}$ & $1.7-0.7 \mathrm{~m}$ & $1.9-1.0 \mathrm{~m}$ \\
\hline 16 & - & - & - & $2.19 \mathrm{~m}$ & $2.22 \mathrm{~m}$ & $2.27 \mathrm{~m}$ & $2.28 \mathrm{~m}$ & $2.30 \mathrm{~m}$ & $2.33 \mathrm{~m}$ \\
\hline $17 \mathrm{a}$ & $4.77 \mathrm{br} \mathrm{s}$ & $4.78 \mathrm{br} \mathrm{s}$ & $1.68 \mathrm{~d}(1.3)$ & $3.71 \mathrm{t}(7.3)$ & $3.95 \mathrm{dd}(7.5 ; 9.6)$ & $3.76 \mathrm{dd}(7.5 ; 9.4)$ & $4.19 \mathrm{dd}(8.0 ; 10.8)$ & $3.82 \mathrm{t}(8.4)$ & $3.83 \mathrm{dd}(8.4 ; 9.4)$ \\
\hline $17 \mathrm{~b}$ & $4.71 \mathrm{br} \mathrm{s}$ & $4.71 \mathrm{br} \mathrm{s}$ & & $3.54 \mathrm{dd}(3.9 ; 7.7)$ & $3.55 \mathrm{dd}(8.0 ; 9.6)$ & $3.46 \mathrm{dd}(8.6 ; 9.2)$ & $4.09 \mathrm{dd}(8.0 ; 10.8)$ & $3.52 \mathrm{dd}(7.2 ; 9.5)$ & $3.53 \mathrm{dd}(7.2 ; 9.6)$ \\
\hline 18 & $0.93 \mathrm{~s}$ & $1.00 \mathrm{~s}$ & $1.00 \mathrm{~s}$ & $1.16 \mathrm{~s}$ & $1.16 \mathrm{~s}$ & $1.16 \mathrm{~s}$ & $1.16 \mathrm{~s}$ & $0.93 \mathrm{~s}$ & $1.16 \mathrm{~s}$ \\
\hline $19 \mathrm{a}$ & $3.90-3.10 \mathrm{~m}$ & $4.08 \mathrm{dd}(2.2 ; 9.6)$ & $4.08 \mathrm{dd}(2.2 ; 9.6)$ & - & - & - & - & $3.70 \mathrm{~d}(10.9)$ & - \\
\hline $19 \mathrm{~b}$ & & $3.40-3.10 \mathrm{~m}$ & $3.40-3.10 \mathrm{~m}$ & - & - & - & - & $3.33-3.30 \mathrm{~m}$ & - \\
\hline 20 & $1.04 \mathrm{~s}$ & $1.07 \mathrm{~s}$ & $1.07 \mathrm{~s}$ & $0.81 \mathrm{~s}$ & $0.81 \mathrm{~s}$ & $0.81 \mathrm{~s}$ & $0.81 \mathrm{~s}$ & $1.03 \mathrm{~s}$ & $0.85 \mathrm{~s}$ \\
\hline 21 & - & - & - & $3.63 \mathrm{~s}$ & $3.64 \mathrm{~s}$ & $3.64 \mathrm{~s}$ & $3.64 \mathrm{~s}$ & - & $3.63 \mathrm{~s}$ \\
\hline $1^{\prime}$ & $6.10 \mathrm{~d}(3.6)$ & $4.18 \mathrm{t}(7.6)$ & $4.18 \mathrm{t}(7.6)$ & $5.69 \mathrm{~d}(5.2)$ & $4.52 \mathrm{~d}(8.0)$ & $5.08 \mathrm{~d}(3.7)$ & - & $4.77 \mathrm{~d}(3.8)$ & $4.77 \mathrm{~d}(3.8)$ \\
\hline $2^{\prime}$ & $\begin{array}{l}3.54 \mathrm{dd} \\
(3.6 ; 9.5)\end{array}$ & & & $4.31 \mathrm{dd}(4.0 ; 5.1)$ & $4.97 \mathrm{dd}(8.0 ; 9.5)$ & $4.83 \mathrm{dd}(3.8 ; 10.2)$ & - & $3.37 \mathrm{dd}(3.8 ; 9.7)$ & $3.38 \mathrm{dd}(3.8 ; 9.7)$ \\
\hline $3^{\prime}$ & & $3.40-3.10 \mathrm{~m}$ & $3.40-3.10 \mathrm{~m}$ & $5.19 \mathrm{t}(2.8)$ & $5.20 \mathrm{t}(9.5)$ & $5.46 \mathrm{t}(9.8)$ & - & $3.69-3.55 \mathrm{~m}$ & $3.69-3.60 \mathrm{~m}$ \\
\hline $4^{\prime}$ & & & & $4.90 \mathrm{dd}(2.6 ; 10.2)$ & $5,08 \mathrm{t}(9.6)$ & $5.03 \mathrm{t}(9.8)$ & - & $3.27 \mathrm{t}(9.6)$ & $3.27 \mathrm{t}(9.7)$ \\
\hline $5^{\prime}$ & $3.90-3.10 \mathrm{~m}$ & & & $3.95 \mathrm{~m}$ & $3.68 \mathrm{~m}$ & $4.03 \mathrm{~m}$ & - & $3.69-3.55 \mathrm{~m}$ & $3.69-3.60 \mathrm{~m}$ \\
\hline $6^{\prime} \mathrm{a}$ & & $3.86 \mathrm{dd}(2.1 ; 11.8)$ & $3.86 \mathrm{dd}(2.1 ; 11.8)$ & $4.20 \mathrm{~d}(4.4)$ & $4.26 \mathrm{dd}(4.5 ; 12.0)$ & $4.24 \mathrm{dd}(4.8 ; 12.3)$ & - & $3.80 \mathrm{dd}(2.2 ; 11.6)$ & $3.80 \mathrm{dd}(2.2 ; 11.4)$ \\
\hline $6^{\prime} \mathrm{b}$ & & $3.68 \mathrm{dd}(4.9 ; 11.8)$ & $3.68 \mathrm{dd}(4.9 ; 11.8)$ & & $4.14 \mathrm{dd}(2.5 ; 12.5)$ & $4.10 \mathrm{dd}(2.3 ; 12.3)$ & - & $3.69-3.55 \mathrm{~m}$ & $3.69-3.60 \mathrm{~m}$ \\
\hline $8^{\prime}$ & - & - & - & $1.73 \mathrm{~s}$ & - & - & - & - & - \\
\hline $\mathrm{CH}_{3} \mathrm{CO}$ & & & & & $2.08 \mathrm{~s}$ & $2.09 \mathrm{~s}$ & & & \\
\hline
\end{tabular}


Table 2. ${ }^{13} \mathrm{C}$ NMR data $\left(\delta \mathrm{ppm}, \mathrm{CDCl}_{3}\right)$ for compounds $\mathbf{1}-\mathbf{1 6}$

\begin{tabular}{|c|c|c|c|c|c|c|c|c|c|}
\hline $\mathrm{C}$ & 1 & 2 & 3 & 4 & 5 & 6 & 7 & $8 a$ & $8 b$ \\
\hline 1 & 40.7 & 40.8 & 40.5 & 40.8 & - & 40.4 & 40.4 & 39.7 & 39.9 \\
\hline 2 & 19.1 & 19.1 & 18.3 & 19.2 & - & 18.3 & 18.3 & 18.2 & 18.2 \\
\hline 3 & 37.7 & 38.1 & 35.6 & 38.1 & - & 36.1 & 36.4 & 36.3 & 36.3 \\
\hline 4 & 43.2 & 43.8 & 38.7 & 43.7 & - & 37.4 & 37.1 & 37.8 & 37.8 \\
\hline 5 & 57.1 & 57.1 & 56.9 & 57.0 & - & 56.8 & 56.9 & 56.6 & 56.3 \\
\hline 6 & 21.8 & 21.9 & 20.5 & 22.3 & - & 20.5 & 20.5 & 20.8 & 20.5 \\
\hline 7 & 41.3 & 41.3 & 41.6 & 42.1 & - & 41.6 & 41.6 & 41.6 & 44.0 \\
\hline 8 & 44.2 & 44.2 & 44.2 & 44.2 & - & 44.2 & 44.2 & 44.2 & 49.2 \\
\hline 9 & 55.1 & 55.1 & 56.2 & 56.4 & - & 56.2 & 56.2 & 56.2 & 49.1 \\
\hline 10 & 39.7 & 39.4 & 39.2 & 39.5 & - & 39.2 & 39.2 & 39.2 & 39.4 \\
\hline 11 & 18.4 & 18.4 & 18.2 & 19.2 & - & 18.2 & 18.2 & 18.7 & 19.6 \\
\hline 12 & 33.1 & 33.1 & 33.2 & 26.0 & - & 33.2 & 33.2 & 33.2 & 25.0 \\
\hline 13 & 43.8 & 43.8 & 44.0 & 37.0 & - & 44.0 & 44.0 & 43.8 & 44.9 \\
\hline 14 & 39.7 & 39.7 & 39.7 & 40.4 & - & 39.7 & 39.7 & 40.5 & 40.4 \\
\hline 15 & 48.9 & 48.9 & 49.1 & 43.8 & - & 49.1 & 49.1 & 49.0 & 135.4 \\
\hline 16 & 155.9 & 155.9 & 155.8 & 43.3 & - & 155.8 & 155.8 & 155.8 & 142.5 \\
\hline 17 & 103.0 & 102.9 & 103.0 & 64.2 & - & 103.0 & 103.0 & 103.0 & 15.4 \\
\hline 18 & 29.0 & 28.7 & 27.1 & 28.7 & - & 27.8 & 27.6 & 27.4 & 27.5 \\
\hline 19 & 184.8 & 178.1 & 65.6 & 178.2 & - & 65.9 & 67.2 & 73.7 & 73.7 \\
\hline 20 & 15.6 & 15.4 & 18.1 & 15.4 & - & 18.2 & 18.1 & 18.2 & 18.1 \\
\hline 21 & - & 51.1 & - & 51.1 & - & - & - & - & - \\
\hline $1^{\prime}$ & - & - & - & - & 86.6 & 96.8 & - & 101.7 & 101.7 \\
\hline $2^{\prime}$ & - & - & - & - & 70.1 & 73.3 & - & 73.3 & 73.3 \\
\hline $3^{\prime}$ & - & - & - & - & 72.1 & 70.3 & - & 72.0 & 72.0 \\
\hline $4^{\prime}$ & - & - & - & - & 67.2 & 68.2 & - & 71.7 & 71.7 \\
\hline $5^{\prime}$ & - & - & - & - & 70.6 & 67.0 & - & 69.1 & 69.1 \\
\hline $6^{\prime}$ & - & - & - & - & 61.0 & 63.1 & - & 62.1 & 62.1 \\
\hline $7^{\prime}$ & - & - & - & - & - & 121.5 & - & - & - \\
\hline $8^{\prime}$ & - & - & - & - & - & 20.7 & - & - & - \\
\hline \multirow[t]{4}{*}{$-\mathrm{COCH}_{3}$} & - & - & - & - & 20.5 & 20.8 & 21.1 & 20.6 & 20.6 \\
\hline & - & - & - & - & 20.6 & 20.8 & - & 20.6 & 20.6 \\
\hline & - & - & - & - & 20.6 & 20.9 & - & 20.7 & 20.7 \\
\hline & - & - & - & - & 20.7 & - & - & 20.8 & 20.8 \\
\hline \multirow[t]{4}{*}{$-\mathrm{COCH}_{3}$} & - & - & - & - & 169.5 & 169.2 & 171.4 & 169.2 & 169.2 \\
\hline & - & - & - & - & 169.8 & 169.7 & - & 169.4 & 169.4 \\
\hline & - & - & - & - & 169.9 & 170.7 & - & 170.4 & 170.4 \\
\hline & - & - & - & - & 170.5 & - & - & 170.7 & 170.7 \\
\hline $\mathrm{C}$ & $9^{*}$ & $10 \mathrm{a}^{*}$ & $10 b^{*}$ & 11 & 12 & 13 & 14 & $15^{*}$ & $16^{*}$ \\
\hline 1 & 40.9 & 40.9 & 40.9 & 40.2 & 40.8 & 41.1 & 40.9 & 41.6 & 41.6 \\
\hline 2 & 19.5 & 19.6 & 19.6 & 19.1 & 19.2 & 19.6 & 19.3 & 20.2 & 20.4 \\
\hline 3 & 36.8 & 37.6 & 37.6 & 38.0 & 38.1 & 38.5 & 38.3 & 36.9 & 39.3 \\
\hline 4 & 39.9 & 39.3 & 39.3 & 43.7 & 43.8 & 44.2 & 44.0 & 39.9 & 45.2 \\
\hline 5 & 58.4 & 58.5 & 58.2 & 56.9 & 57.0 & 57.4 & 57.2 & 59.2 & 58.4 \\
\hline 6 & 21.5 & 21.7 & 20.7 & 22.2 & 22.2 & 22.6 & 22.4 & 21.9 & 23.5 \\
\hline 7 & 43.0 & 43.1 & 45.0 & 42.0 & 42.1 & 42.4 & 42.2 & 44.0 & 43.4 \\
\hline 8 & 45.5 & 45.5 & 50.6 & 44.1 & 44.3 & 44.7 & 44.5 & 45.7 & 45.6 \\
\hline 9 & 57.9 & 57.9 & 50.8 & 56.3 & 56.5 & 56.8 & 56.5 & 58.5 & 58.0 \\
\hline 10 & 40.6 & 40.6 & 40.8 & 39.3 & 39.5 & 39.8 & 39.6 & 40.6 & 40.8 \\
\hline 11 & 19.4 & 19.4 & 20.0 & 19.1 & 19.1 & 19.5 & 19.2 & 19.5 & 20.4 \\
\hline 12 & 34.4 & 34.4 & 26.2 & 25.8 & 25.9 & 26.3 & 26.2 & 27.4 & 27.4 \\
\hline 13 & 45.5 & 45.5 & 46.4 & 37.1 & 37.3 & 37.6 & 37.5 & 39.3 & 39.1 \\
\hline 14 & 41.9 & 41.9 & 41.4 & 40.7 & 39.8 & 40.6 & 40.5 & 42.0 & 42.1 \\
\hline 15 & 50.4 & 50.4 & 136.8 & 43.8 & 44.0 & 44.2 & 43.9 & 46.1 & 45.8 \\
\hline 16 & 156.9 & 157.0 & 143.5 & 40.0 & 40.3 & 40.2 & 39.3 & 41.5 & 41.6 \\
\hline 17 & 103.8 & 103.8 & 15.6 & 64.9 & 71.6 & 70.3 & 66.2 & 71.1 & 71.1 \\
\hline 18 & 28.0 & 28.5 & 28.6 & 28.7 & 28.7 & 29.1 & 28.9 & 28.0 & 29.3 \\
\hline 19 & 65.3 & 73.9 & 74.0 & 178.0 & 178.0 & 178.4 & 178.3 & 65.3 & 179.9 \\
\hline 20 & 19.0 & 19.0 & 18.9 & 15.3 & 15.4 & 15.7 & 15.6 & 19.1 & 16.2 \\
\hline 21 & - & - & - & 51.0 & 51.1 & 51.1 & 51.3 & - & 51.8 \\
\hline $1^{\prime}$ & 93.6 & 105.2 & 105.2 & 96.8 & 100.8 & 96.2 & - & 100.4 & 100.4 \\
\hline $2^{\prime}$ & 72.4 & 75.4 & 75.4 & 73.0 & 72.9 & 71.4 & - & 73.9 & 73.9 \\
\hline $3^{\prime}$ & 76.1 & 78.4 & 78.4 & 70.1 & 71.8 & 70.3 & - & 73.8 & 73.8 \\
\hline $4^{\prime}$ & 71.2 & 71.8 & 71.8 & 68.2 & 71.4 & 69.1 & - & 72.1 & 72.1 \\
\hline $5^{\prime}$ & 74.9 & 77.9 & 77.9 & 66.9 & 68.5 & 67.5 & - & 75.0 & 75.3 \\
\hline
\end{tabular}


Table 2 (continued)

\begin{tabular}{|c|c|c|c|c|c|c|c|c|c|}
\hline $\mathrm{C}$ & $9^{*}$ & $10 a^{*}$ & $10 b^{*}$ & 11 & 12 & 13 & 14 & $15^{*}$ & $16^{*}$ \\
\hline $6^{\prime}$ & 62.4 & 62.9 & 62.9 & 63.1 & 62.1 & 62.5 & - & 63.0 & 62.9 \\
\hline $7^{\prime}$ & 21.1 & - & - & 121.2 & - & - & - & - & - \\
\hline $8^{\prime}$ & 171.8 & - & - & 20.8 & - & - & - & - & - \\
\hline \multirow[t]{4}{*}{$-\mathrm{COCH}_{3}$} & - & - & - & 20.6 & 20.6 & 21.0 & 21.3 & - & - \\
\hline & & & & 20.7 & 20.6 & 21.0 & - & & \\
\hline & & & & 20.8 & 20.7 & 21.1 & - & & \\
\hline & & & & - & 20.7 & 21.1 & - & & \\
\hline \multirow[t]{4}{*}{$-\mathrm{COCH}_{3}$} & & & & 169.1 & 169.2 & 170.0 & 171.6 & & \\
\hline & & & & 169.6 & 169.4 & 170.5 & - & & \\
\hline & & & & 170.6 & 170.3 & 170.6 & - & & \\
\hline & & & & - & 170.7 & 171.0 & - & & \\
\hline
\end{tabular}

Table 3. Results of the in vitro assays of compounds $1-4,9,10 \mathbf{a} / \mathbf{b}, \mathbf{1 5}, 16$ and gentian violet against bloodstream trypomastigotes of Trypanosoma cruzi $\mathrm{Y}$ strain

\begin{tabular}{|c|c|c|c|c|c|}
\hline \multirow[t]{2}{*}{ Compound } & \multicolumn{5}{|c|}{ Concentrations $(\mathrm{mM}) \times \%$ parasite lysis } \\
\hline & 0.31 & 0.63 & 1.25 & 2.50 & 5.00 \\
\hline 1 & 0 & $90(\mathrm{H})$ & $100(\mathrm{TH})$ & $100(\mathrm{TH})$ & $100(\mathrm{TH})$ \\
\hline 2 & 45 & 48 & 88 & 100 & 100 \\
\hline 4 & 45 & $94(\mathrm{H})$ & $100(\mathrm{H})$ & $100(\mathrm{H})$ & $100(\mathrm{H})$ \\
\hline 3 & NT & NT & 66 & 72 & 100 \\
\hline 9 & NT & NT & 0 & 0 & 56 \\
\hline $10 a / b$ & NT & NT & 0 & 0 & 36 \\
\hline 15 & NT & NT & 0 & 38 & 55 \\
\hline 16 & 51 & 96 & 100 & 100 & 100 \\
\hline $\mathrm{NC}$ & 0 & 0 & 0 & 0 & 0 \\
\hline Gentian violet & 67 & 100 & 100 & 100 & NT \\
\hline
\end{tabular}

NC, negative control (1\% DMSO + TCM199); NT, not tested; H, partial haemolysis; TH, total haemolysis.

a rapid decline in the number of blood parasites is observed. ${ }^{8}$ Swiss male albino mice (18-20 g) were intraperitoneally inoculated with blood trypomastigotes of T. cruzi $\mathrm{Y}$ strain and, at the peak of parasitaemia (7th day), a single dose of $250 \mathrm{mg} / \mathrm{kg}$ of the compounds was given by oral route. The number of circulating bloodstream forms was microscopically determined, before injection and 4 and $6 \mathrm{~h}$ later. Untreated mice similarly inoculated were used as negative controls and benznidazole (Rochagan ${ }^{\circledR}$, Roche) at a dose of $250 \mathrm{mg} / \mathrm{kg}$ served as positive control. Groups of three mice were used in all experiments. The results are shown in Table 4. Parasitaemia reductions determined with benznidazole ( $4 \mathrm{~h} 91.7 \pm 3.9 \% ; 6 \mathrm{~h} 92.6 \pm 3.5 \%$ ) and for untreated mice ( 4 h $29.6 \pm 10.5 \%$; 6 h $23.3 \pm 11.9 \%$ ) showed statistically significant difference and are clearly indicative of positive and negative control, respectively. For compounds $\mathbf{2}$ and $\mathbf{1 6}$ parasitaemia reductions were significantly higher than those of the negative control both at 4 and $6 \mathrm{~h}$ and for each compound the parasitaemias were equivalent after 4 and $6 \mathrm{~h}$. Moreover, at of $4 \mathrm{~h}$, there was no significant reduction in parasitaemia between mice treated with $\mathbf{1 6}$ and the group of the standard drug benznidazole (positive control). Thus, both these ent-kaurane derivatives have shown in vivo trypanocidal activity. The result for $\mathbf{1 6}$ is remarkable for the observed equivalence with benznidazole after $4 \mathrm{~h}$ of administration. On the other hand, its effect significantly decreases after $6 \mathrm{~h}$ while the one of benznidazole is maintained at the same level. This might be explained by the possible hydrolysis of the ester and/or glycosidic functions.

Table 4. Results of in vivo assays of compounds $\mathbf{2}$ and $\mathbf{1 6}$ in mice in the acute phase of Trypanosoma cruzi infection by the rapid method ${ }^{8}$

\begin{tabular}{|c|c|c|}
\hline \multirow[t]{2}{*}{ Compounds } & \multicolumn{2}{|c|}{ Parasitaemia reductions $(\%)$ (means $\pm \mathrm{SD}^{*}$ ) } \\
\hline & $T=4 \mathrm{~h}$ & $T=6 \mathrm{~h}$ \\
\hline $\mathrm{NC}$ & $29.6 \pm 10.5^{\mathrm{aA}}$ & $23.3 \pm 11.9^{\mathrm{b} A}$ \\
\hline 2 & $56.5 \pm 18.2^{\mathrm{aB}}$ & $51.5 \pm 13.3^{\mathrm{bB}}$ \\
\hline 16 & $70.3 \pm 13.3^{\mathrm{aBC}}$ & $68.0 \pm 10.5^{\mathrm{aB}}$ \\
\hline PC (Benznidazole) & $91.7 \pm 3.9^{\mathrm{aC}}$ & $92.6 \pm 3.5^{\mathrm{aC}}$ \\
\hline
\end{tabular}

NC, negative control (1\% DMSO + TCM199); PC, positive control; $T$, time in hours after administration to mice, in the 7 th day after inoculation with trypomastigotes of $T$. cruzi Y strain. a, b-comparison in the same line. A, B, C-comparison in the same column.

${ }^{*} P<0.05$. 
The results of the in vitro assays for $\mathbf{1 5}$ and $\mathbf{1 6}$ (Table 3) indicate that an ester group at C19 makes a significant contribution to the trypanocidal activity that decreases for $\mathrm{C} 19$-alcohols (3 and 15) and $\mathrm{C} 19-O$-glucosides $(\mathbf{1 0 a} / \mathbf{b})$. The double bond between $\mathrm{C} 16$ and $\mathrm{C} 17$ is not essential for the activity, since the trypanocidal effect is increased after its hydroxylation, as can be deduced by comparing the effects of $\mathbf{2}$ and $\mathbf{4}$ (Table 3). Considering the in vitro profile of compounds $\mathbf{4}$ and $\mathbf{1 6}$, one can conclude that glycosidation of $\mathbf{4}$ does not affect the trypanocidal activity, but the undesirable haemolytic effect is supressed. Moreover, the good profile of $\mathbf{1 6}$ in the in vitro and in vivo assays might be attributed to more favourable pharmacokinetic properties since the glycosyl moiety attached to the kaurane skeleton must increase its hydrophilicity and influence the transport through the cell membrane. ${ }^{23}$ For this reason, the present results support the quest for more polar derivatives of kaurenoic acid.

In addition, it should be pointed out that the utility of the rapid in vivo method as a screening technique permits the evaluation of the trypanocidal activity in a short period of time $(6 \mathrm{~h})$ only requiring a small number of test animals. Besides, as it has been originally described by Filardi \& Brener, ${ }^{8}$ this method shows a fairly good correlation with those obtained by prolonged treatment schedules used to assess the action of drugs in experimental Chagas' disease. ${ }^{8}$ Thus, compounds 2 and 16 can be considered promising chemotherapeutic agents deserving further evaluations.

\section{Experimental}

\subsection{Chemistry}

Melting points were taken with a Microquímica apparatus APF-301 and uncorrected. Optical rotations were measured with a Bellinghan \& Stanley P20 polarimeter. IR spectra were obtained on a Perkin-Elmer FTIR spectrophotometer in diamond film. NMR spectra were recorded at $400 \mathrm{MHz}$ for ${ }^{1} \mathrm{H}$ and $100 \mathrm{MHz}$ for ${ }^{13} \mathrm{C}$ in deuterochloroform or deuteromethanol, added of TMS as internal reference, on a Bruker DRX 400. Chemical shift values are expressed in ppm and coupling constants $(J)$ in $\mathrm{Hz}$. Column chromatography (CC) and flash column chromatography (FCC) were performed on silica gel Merck $60(0.063-0.200$ and $0.040-0.063 \mathrm{~mm}$, respectively). HRMS were run in a VG TS-250 spectrometer working at $70 \mathrm{eV}$. TLC were carried out on silica gel Merck $60 \mathrm{~F}_{254}(0.25 \mathrm{~mm}$ thick). Solvents and reagents were purified by standard procedures.

3.1.1. ent-Kaur-16-en-19-oic acid (kaurenoic acid) (1). It was obtained from Wedelia paludosa ethanol extract, as described previously. ${ }^{11}$

3.1.2. Methyl ent-kaur-16-en-19-oate (2). It was obtained from kaurenoic acid (1) $(500 \mathrm{mg})$ by usual procedure with an ethereal solution $(100 \mathrm{~mL})$ of diazomethane giving the ester $2(527 \mathrm{mg})$ in quantitative yield. ${ }^{10}$
3.1.3. ent-Kaur-16-en-19-ol (3). $\mathrm{LiAlH}_{4} \quad(146 \mathrm{mg}$, $3.84 \mathrm{mmol}$ ) was added to a solution of methyl ester 2 $(135 \mathrm{mg}, 0.427 \mathrm{mmol})$ in dry THF $(5 \mathrm{~mL})$. After $3 \mathrm{~h}$ reflux, the $\mathrm{LiAlH}_{4}$ excess was consumed by adding EtOAc $(1 \mathrm{~mL})$ and water (10 drops), under external cooling. The mixture was washed with diluted $\mathrm{NaOH}$, concentrated under reduced pressure and submitted to $\mathrm{CC}$, eluting with $\mathrm{CH}_{2} \mathrm{Cl}_{2} / \mathrm{AcOEt}$ (9:1) to give 3 (119 mg, $97 \%$ ), mp $133-135^{\circ} \mathrm{C}\left(\right.$ lit. $\left.^{10} 134-138^{\circ} \mathrm{C}\right)$. $[\alpha]_{\mathrm{D}}^{25}-72.1^{\circ}$ (c 1.10, $\left.\mathrm{CH}_{2} \mathrm{Cl}_{2}\right)$. IR $\left(v_{\max } / \mathrm{cm}^{-1}\right): 3393,2922,2856$, $1657,1440,1367,1022,1005,878 .{ }^{1} \mathrm{H}$ NMR data, Table 1. ${ }^{13} \mathrm{C}$ NMR data, Table 2. HRMS (FAB-POSI, M+1) Calcd 289.2531. Found: 289.2533.

3.1.4. Methyl-ent-17-hydroxy-16 $\alpha$-kauran-19-oate (4). The methyl ester $2(302 \mathrm{mg}, 0.956 \mathrm{mmol})$ in dry THF $(20 \mathrm{~mL})$ was treated with diborane generated in situ by adding $\mathrm{NaBH}_{4}(364 \mathrm{mg}, 9.62 \mathrm{mmol})$ followed by $\mathrm{BF}_{3} \cdot \mathrm{OEt}_{2}$ (dropwise, $1.2 \mathrm{~mL}, 9.6 \mathrm{mmol}$ ). After stirring for $2 \mathrm{~h}$ at room temperature under an argon atmosphere, EtOH $(10 \mathrm{~mL}), 5 \mathrm{M} \mathrm{NaOH}(10 \mathrm{~mL})$ and $30 \%$ $\mathrm{H}_{2} \mathrm{O}_{2}(5 \mathrm{~mL})$ were added at $0{ }^{\circ} \mathrm{C}$. Stirring was then continued for $1 \mathrm{~h}$ at $50^{\circ} \mathrm{C}$. The THF was evaporated and the residue was dissolved in EtOAc and partitioned with saturated $\mathrm{NaCl}$ solution $(2 \times 100 \mathrm{~mL})$. The organic layer was dried $\left(\mathrm{Na}_{2} \mathrm{SO}_{4}\right)$ and concentrated under reduced pressure. The recovered product was purified by FCC eluting with $n$-hexane/EtOAc (9:1) to yield $4(276 \mathrm{mg}$, $86 \%)$. Gum (lit. ${ }^{24}$ gum), $[\alpha]_{\mathrm{D}}^{25}-68.1^{\circ}\left(\mathrm{c} 0.99, \mathrm{CH}_{2} \mathrm{Cl}_{2}\right)$. IR $\left(v_{\max } / \mathrm{cm}^{-1}\right): 3379,2983,2931,2855,1726,1462$, 1448, 1375, 1234, 1213, 1192, 1154, 1097, 1032, 1012, 997. ${ }^{1} \mathrm{H}$ NMR data, Table $1 .{ }^{13} \mathrm{C}$ NMR data, Table 2. HRMS (FAB-POSI, M+1) Calcd 335.2586. Found: 335.2588 .

3.1.5. 2,3,4,6-Tetra- $O$-acetyl- $\alpha$-D-glucopyranosyl bromide (5). It was obtained from peracetylated $\beta$-D-glucopyranose $(1,2,3,4,6$-penta- $O$-acetyl- $\beta$-D-glucopyranose $)$ $(1.01 \mathrm{~g}, 2.58 \mathrm{mmol})$ by standard procedure ${ }^{25}$ to yield $\mathbf{5}$ (865 mg, 81\%).

3.1.6. (2S)-2-Methyl-2-O-ent-kaur-16-en-19-yl-(3,4,6tri- $O$-acetyl-1,2-dideoxy- $\alpha$-D-glucopyranoso)[2,1- $d]$-1,3dioxolane (6). A solution of the glucopyranosyl bromide $5(152 \mathrm{mg}, 0.369 \mathrm{mmol})$ in toluene $(5 \mathrm{~mL})$ was added to the kaurene alcohol $3(85 \mathrm{mg}, 0.30 \mathrm{mmol})$ in dry toluene $(15 \mathrm{~mL})$ following addition of $\mathrm{Hg}(\mathrm{CN})_{2}(92 \mathrm{mg}, 0.36 \mathrm{mmol})$. The mixture was kept under a nitrogen atmosphere and was stirred at room temperature for $24 \mathrm{~h}$ and then at $80^{\circ} \mathrm{C}$ for a further $66 \mathrm{~h}$. The reaction mixture was washed with $5 \%$ $\mathrm{NaHCO}_{3}(2 \times 50 \mathrm{~mL})$ and $10 \%$ KI $(2 \times 50 \mathrm{~mL})$, dried $\left(\mathrm{Na}_{2} \mathrm{SO}_{4}\right)$ and concentrated under reduced pressure $\left(70{ }^{\circ} \mathrm{C}\right)$. The residue was submitted to $\mathrm{FCC}$ eluting with $n$-hexane/EtOAc $(9: 1)$ to recuperate 3 ( $20 \mathrm{mg}$, $0.07 \mathrm{mmol}$ ) and affording the kaurene acetate 7 (19 mg, 25\%) and orthoester $6(62 \mathrm{mg}, 44 \%)$. Orthoester 6: colourless oil, $[\alpha]_{\mathrm{D}}^{25}+30.0^{\circ}\left(c \quad 0.20, \mathrm{CHCl}_{3}\right)$. IR $\left(v_{\max } / \mathrm{cm}^{-1}\right): 2923,1742,1657,1442,1369,1384$, $1253,1215,1117,1048,1030,982,910,885 .{ }^{1} \mathrm{H}$ NMR data, Table $1 .{ }^{13} \mathrm{C}$ NMR data, Table 2. HRMS (FAB-POSI, M+1) Calcd 619.3482. Found: 619.3417. 
3.1.7. ent-Kaur-16-en-19-yl acetate (7). The kaurene acetate 7 was obtained as a white solid, $\mathrm{mp} 105-107^{\circ} \mathrm{C}$ (lit. $\left.{ }^{10} 104-108^{\circ} \mathrm{C}\right)$. $[\alpha]_{\mathrm{D}}^{25}-56.8^{\circ}\left(c \quad 0.22, \mathrm{CHCl}_{3}\right)$. IR $\left(v_{\max } / \mathrm{cm}^{-1}\right): 2922,1732,1658,1452,1442,1368,1294$, 1237, 1195, 1033, 880. ${ }^{1} \mathrm{H}$ NMR data, Table $1 .{ }^{13} \mathrm{C}$ NMR data, Table 2. HRMS (FAB-POSI, M+1) Calcd 331.2637. Found: 331.2661.

3.1.8. Mixture of ent-kaur-16-en-19-yl and ent-kaur15-en-19-yl 2,3,4,6-tetra- $O$-acetyl- $\beta$-D-glucopyranosides $(\mathbf{8 a} / \mathbf{b})$. A solution of the glucopyranosyl bromide $\mathbf{5}$ $(680 \mathrm{mg}, 1.65 \mathrm{mmol})$ in toluene $(15 \mathrm{~mL})$ was added to the kaurene alcohol $3(308 \mathrm{mg}, 1.07 \mathrm{mmol})$ in dry toluene $(30 \mathrm{~mL})$ and treated with $\mathrm{Hg}(\mathrm{CN})_{2}(450 \mathrm{mg}, 1.78 \mathrm{mmol})$. The mixture was immediately heated at $80^{\circ} \mathrm{C}$ and stirred for $140 \mathrm{~h}$, under nitrogen atmosphere. The organic solution was washed with $5 \% \mathrm{NaHCO}_{3}(2 \times 150 \mathrm{~mL})$ and $10 \% \mathrm{KI}(2 \times 150 \mathrm{~mL})$, dried $\left(\mathrm{Na}_{2} \mathrm{SO}_{4}\right)$ and concentrated under reduced pressure $\left(70^{\circ} \mathrm{C}\right)$. The residue was submitted to FCC eluting with $n$-hexane/EtOAc (9:1) to afford the kaurene acetate $7(175 \mathrm{mg}, 50 \%)$ and a $1: 1$ mixture of $\mathbf{8 a} / \mathbf{b}(223 \mathrm{mg}, 34 \%)$. Glucosides $\mathbf{8 a} / \mathbf{b}$ (1:1): white solid, $\operatorname{mp~} 144-146^{\circ} \mathrm{C},[\alpha]_{\mathrm{D}}^{25}-88.9^{\circ}\left(c 0.18, \mathrm{CHCl}_{3}\right)$. IR $\left(v_{\max } /\right.$ $\mathrm{cm}^{-1}$ ): 2922, 2853, 1747, 1445, 1368, 1229, 1170, 1086, 1066, 1037, 908, 894, 813. ${ }^{1} \mathrm{H}$ NMR data, Table $1 .{ }^{13} \mathrm{C}$ NMR data, Table 2. HRMS (FAB-POSI, $\mathrm{M}+\mathrm{Na}$ ) Calcd 641.3301. Found: 641.3267.

3.1.9. ent-Kaur-16-en-19-yl 2-O-acetyl- $\alpha$-D-glucopyranoside (9). The orthoester 6 (48 $\mathrm{mg}, 0.08 \mathrm{mmol})$ in $\mathrm{CH}_{3} \mathrm{OH} / \mathrm{Et}_{3} \mathrm{~N} / \mathrm{H}_{2} \mathrm{O}(8: 1: 1)(5 \mathrm{~mL})$ was stirred at room temperature for $24 \mathrm{~h}$. The solution was concentrated under reduced pressure $\left(50^{\circ} \mathrm{C}\right)$ and submitted to FCC eluting with $n$-hexane/EtOAc (1:1) to give 9 as colourless needles $(28 \mathrm{mg}, 73 \%)$, mp $136-137^{\circ} \mathrm{C},[\alpha]_{\mathrm{D}}^{25}+7.4^{\circ}(c$ 0.54, MeOH). IR $\left(v_{\max } / \mathrm{cm}^{-1}\right): 3359,2965,2923,1723$, 1657, 1439, 1368, 1247, 1150, 1022, 877. ${ }^{1} \mathrm{H}$ NMR data, Table $1 .{ }^{13} \mathrm{C}$ NMR data, Table 2. HRMS (FAB-POSI, $\mathrm{M}+\mathrm{Na}$ ) Calcd 493.3165. Found: 493.3156.

3.1.10. ent-Kaur-16-en-19-yl and ent-kaur-15-en-19-yl $\beta$ D-glucopyranosides $(\mathbf{1 0 a} / \mathbf{b})$. The 1:1 mixture of peracetylated glucosides $\mathbf{8 a} / \mathbf{b}(205 \mathrm{mg}, 0.33 \mathrm{mmol})$ in dry methanol $(8 \mathrm{~mL})$ was treated with sodium methoxide (80 mg, $1.48 \mathrm{mmol})$ and stirred at room temperature for $4 \mathrm{~h}$. The solution was neutralized with an excess of Amberlite IR $120\left(\mathrm{H}^{+}\right)$resin, filtered and evaporated. The residue was submitted to FCC (EtOAc/ $\mathrm{MeOH}, 8: 2$ ), affording a 1:1 mixture of glucosides $\mathbf{1 0 a} / \mathbf{b}$ as colourless needles $(139 \mathrm{mg}, 93 \%), \mathrm{mp} \mathrm{193-}$ $194^{\circ} \mathrm{C},[\alpha]_{\mathrm{D}}^{25}-46.7^{\circ}(c 0.30, \mathrm{MeOH})$. IR $\left(v_{\max } / \mathrm{cm}^{-1}\right)$ : $3345,2920,2851,1657,1444,1369,1270,1164,1105$, 1073, 1017, 872. ${ }^{1} \mathrm{H}$ NMR data, Table $1 .{ }^{13} \mathrm{C}$ NMR data, Table 2. HRMS (FAB-POSI, M+Na) Calcd 451.3060. Found 451.3065.

3.1.11. (2S)-2-Methyl-2-O-ent-19-methoxy-19-oxo-16 $\alpha$ kauran-17-yl-(3,4,6-tri- $O$-acetyl-1,2-dideoxy- $\alpha$-D-glucopyranoso)[2,1-d]-1,3-dioxolane (11). To the kaurane alcohol $4(90 \mathrm{mg}, 0.27 \mathrm{mmol})$ in dry toluene $(15 \mathrm{~mL})$ was added a solution of the glucopyranosyl bromide 5 (200 mg, $0.486 \mathrm{mmol})$ in dry toluene $(5 \mathrm{~mL})$ and $\mathrm{Hg}(\mathrm{CN})_{2}(130 \mathrm{mg}, 0.515 \mathrm{mmol})$. The mixture was stirred at room temperature for $24 \mathrm{~h}$, at $60^{\circ} \mathrm{C}$ for $48 \mathrm{~h}$ and at $80^{\circ} \mathrm{C}$ for further $24 \mathrm{~h}$, always under nitrogen atmosphere. The organic solution was washed with $5 \% \mathrm{NaHCO}_{3}(2 \times 50 \mathrm{~mL})$ and $10 \% \mathrm{KI}$ $(2 \times 50 \mathrm{~mL})$, dried $\left(\mathrm{Na}_{2} \mathrm{SO}_{4}\right)$ and concentrated under reduced pressure $\left(70{ }^{\circ} \mathrm{C}\right)$. The residue was submitted to FCC eluting with $n$-hexane/EtOAc $(9: 1)$ to recuperate $4(42 \mathrm{mg}, 0.13 \mathrm{mmol})$ and to afford the orthoester $11(52 \mathrm{mg}, 54 \%)$ and the glucopyranoside 12 $(29 \mathrm{mg}, 30 \%)$. Orthoester 11: colourless oil, $[\alpha]_{\mathrm{D}}^{25}$ $+25.0^{\circ}\left(c 0.16, \mathrm{CHCl}_{3}\right)$. IR $\left(\mathrm{cm}^{-1}\right): 2880,1740$, $1725,1425,1358,1215,1140,1020,805 .{ }^{1} \mathrm{H}$ NMR data, Table $1 .{ }^{13} \mathrm{C}$ NMR data, Table 2. HRMS (FAB-POSI, M+Na) Calcd 687.3351. Found: 687. 3419.

3.1.12. ent-19-Methoxy-19-oxo-16 $\alpha$-kauran-17-yl2,3,4,6-tetra- $\boldsymbol{O}$-acetyl- $\boldsymbol{\beta}$-D-glucopyranoside (12). It was yielded as white needles, $\mathrm{mp} 152-153^{\circ} \mathrm{C},[\alpha]_{\mathrm{D}}^{25}-93.8^{\circ}$ (c $\left.0.32, \mathrm{CHCl}_{3}\right)$. IR $\left(v_{\max } / \mathrm{cm}^{-1}\right): 2925,2854,1752$, 1717, 1434, 1368, 1215, 1165, 1151, 1066, 1035, 977, 907. ${ }^{1} \mathrm{H}$ NMR data, Table $1 .{ }^{13} \mathrm{C}$ NMR data, Table 2. HRMS (FAB-POSI, M+Na) Calcd 687.3351. Found: 687.3327.

3.1.13. ent-19-methoxy-19-oxo-16 $\alpha$-kauran-17-yl 2,3,4,6tetra- $\boldsymbol{O}$-acetyl- $\alpha$-D-glucopyranoside (13). The kaurane alcohol $4(450 \mathrm{mg}, 1.35 \mathrm{mmol})$ in dry toluene $(30 \mathrm{~mL})$ was treated with the glucopyranosyl bromide $5(720 \mathrm{mg}$, $1.75 \mathrm{mmol})$ in toluene $(15 \mathrm{~mL})$, and $\mathrm{Hg}(\mathrm{CN})_{2}(450 \mathrm{mg}$, $1.78 \mathrm{mmol})$. The reaction mixture was heated at $70^{\circ} \mathrm{C}$ and stirred for $72 \mathrm{~h}$, under nitrogen atmosphere. The organic solution was washed with $5 \% \quad \mathrm{NaHCO}_{3}$ $(2 \times 150 \mathrm{~mL})$ and $10 \% \mathrm{KI}(2 \times 150 \mathrm{~mL})$, dried with $\mathrm{Na}_{2} \mathrm{SO}_{4}$ and concentrated under reduced pressure $\left(70{ }^{\circ} \mathrm{C}\right)$. The residue was submitted to FCC eluting with $n$-hexane/ EtOAc $(8: 2)$ to afford the kaurane acetate $14(129 \mathrm{mg}$, 25\%) and the $\alpha$-glucoside $\mathbf{1 3}$ (334 mg, 37\%). $\alpha$-Glucoside 13: colourless oil, $[\alpha]_{\mathrm{D}}^{25}+54.3^{\circ}\left(c 0.93, \mathrm{CHCl}_{3}\right)$. IR $\left(v_{\max } /\right.$ $\mathrm{cm}^{-1}$ ): 2924, 2857, 1747, 1724,1436, 1367, 1217, 1149, 1032, 909, 774. ${ }^{1} \mathrm{H}$ NMR data, Table $1 .{ }^{13} \mathrm{C}$ NMR data, Table 2. HRMS (FAB-POSI, M+Na) Calcd 687.3356. Found: 687.3403 .

3.1.14. Methyl ent-16 $\alpha$-kauran-17-acetoxy-19-oate (14). The acetate 14 was obtained as a white solid, mp 83$85^{\circ} \mathrm{C},[\alpha]_{\mathrm{D}}^{25}-74.8^{\circ}\left(c 0.53, \mathrm{CHCl}_{3}\right)$. IR $\left(v_{\max } / \mathrm{cm}^{-1}\right)$ : 2985, 2937, 2858, 1736, 1728, 1464, 1449, 1367, 1237, $1157,1099,1033,973 .{ }^{1} \mathrm{H}$ NMR data, Table $1 .{ }^{13} \mathrm{C}$ NMR data, Table 2. HRMS (FAB-POSI, M+1) Calcd 377.2692. Found: 377.2698.

3.1.15. ent-16 $\alpha$-kauran-19-ol-17-yl $\alpha$-D-glucopyranoside (15). Peracetylated $\alpha$-glucoside $13(90 \mathrm{mg}, 0.13 \mathrm{mmol})$ in dry THF $(10 \mathrm{~mL})$ was treated with $\mathrm{LiAlH}_{4}$ (240 mg, $6.32 \mathrm{mmol}$ ) and stirred at room temperature for $1 \mathrm{~h}$. The $\mathrm{LiAlH}_{4}$ excess was consumed by adding EtOAc $(1 \mathrm{~mL})$ and water under external cooling. The mixture was filtered, evaporated under reduced pressure $\left(50^{\circ} \mathrm{C}\right.$ ) and submitted to FCC (EtOAcl $\mathrm{MeOH} 8: 2)$ to give $\alpha$-glucoside 15 as white needles (42 mg, 68\%), mp 224-226 ${ }^{\circ} \mathrm{C},[\alpha]+66.7^{\circ}$ (c 0.24 , $\mathrm{MeOH}) . \quad$ IR $\left(v_{\max } / \mathrm{cm}^{-1}\right): 3361,2916,2850,1450$, 
1356, 1262，1148，1111，1092，1050，1007，855. ${ }^{1} \mathrm{H}$ NMR data, Table $1 .{ }^{13} \mathrm{C}$ NMR data, Table 2. HRMS (FAB-POSI, M+1) Calcd 469.3165. Found: 469.3149.

3.1.16. ent-19-methoxy-19-oxo-16 $\alpha$-kauran-17-yl $\alpha$-Dglucopyranoside (16). To the peracetylated $\alpha$-glucoside $13(91 \mathrm{mg}, 0.13 \mathrm{mmol})$ in dry methanol $(10 \mathrm{~mL})$, sodium methoxide (50 mg, $0.93 \mathrm{mmol}$ ) was added and the reaction mixture was stirred at room temperature for $4 \mathrm{~h}$. The solution was neutralized with an excess of Amberlite IR $120\left(\mathrm{H}^{+}\right)$resin, filtered and evaporated. The residue was submitted to FCC (EtOAc/MeOH 9:1), yielding the $\alpha$-glucoside $\mathbf{1 6}$ as white cubic crystals $(52 \mathrm{mg}, 81 \%), \operatorname{mp} 92-94{ }^{\circ} \mathrm{C},[\alpha]_{\mathrm{D}}^{25}+48.7^{\circ}$ (c 0.26 , $\mathrm{MeOH})$. IR $\left(v_{\max } / \mathrm{cm}^{-1}\right): 3373,2925,1725,1448$, $1370,1235,1215,1191,1148,1101,1011,921,852$, 772. ${ }^{1} \mathrm{H}$ NMR data, Table $1 .{ }^{13} \mathrm{C}$ NMR data, Table 2. HRMS (FAB-POSI, M+Na) Calcd 497.3114. Found: 497.3123.

\subsection{Trypanocidal activity}

3.2.1. In vitro assay against $T$. cruzi trypomastigotes. Bloodstream forms of $T$. cruzi were obtained from albino mice with established $\mathrm{Y}$ strain infections. Blood with a parasite density of $2 \times 10^{6}$ cells $/ \mathrm{mL}$ was introduced into flat-bottomed test tubes $(56 \times 13 \mathrm{~mm})$. Stock solutions of test compounds were prepared by dissolving $0.02 \mathrm{~mol}$ of each one in $1 \%$ DMSO plus TCM199 $(2.0 \mathrm{~mL})$. Aliquots of this solution were mixed with infected blood $(0.2 \mathrm{~mL})$ and TCM199 was added to complete the volume of each tube to $0.4 \mathrm{~mL}$ to obtain final concentrations of $0.31,0.63$, $1.25,2.50$ and $5.0 \mathrm{mM}$ of each compound. Control tubes with DMSO, DMSO plus TCM199, and gentian violet were run in parallel. All tubes were incubated for $24 \mathrm{~h}$ at $4{ }^{\circ} \mathrm{C}$. Thereafter, $5 \mu \mathrm{L}$ of the suspension was examined microscopically and the parasites counted. The trypanocidal activity was expressed as percentage of parasite number reduction in relation to negative control. ${ }^{21}$

3.2.2. Rapid in vivo assay. Adapted from the rapid method originally described by Filardi \& Brener. ${ }^{8}$ Swiss male albino mice, 18-20 g, 30 days old, were inoculated intraperitoneally with $5 \times 10^{4}$ blood trypomastigotes of $T$. cruzi $\mathrm{Y}$ strain. At the peak of parasitaemia (7th day), a single dose of $250 \mathrm{mg} / \mathrm{kg}$ of compounds to be tested, dissolved/suspended in DMSO $(0.1 \mathrm{~mL})$ plus LIT $(0.9 \mathrm{~mL})$ was given by oral route. Benznidazole (Rochagan ${ }^{\circledR}$, Roche; $250 \mathrm{mg} / \mathrm{mL}$ in carboxymethylcellulose plus LIT) was the standard drug used as positive control. Untreated mice similarly inoculated were used as controls. The number of circulating trypomastigotes was determined microscopically just before inoculation and then 4 and $6 \mathrm{~h}$ after compound administration. The percentage of parasitaemia reduction was calculated by comparing the number of parasites counted at each interval of time after compound administration and pre-treatment. All experiments were undertaken with three mice per group. Means and standard deviations were calculated. The Split-Plot test was used for statistical analysis. The differences between groups were determined by using Student's $t$ test for comparing two groups. Significance was established for $P<0.05$.

\section{Acknowledgments}

We thank UESB (Brazil) for supporting R.B. with a Ph.D. fellowship; CNPq (Brazil) for research fellowships to A.B.O. and E.C.; Arturo San Feliciano, University of Salamanca, Spain, for MS spectra; and Ivan Barbosa Machado Sampaio, Federal University of Minas Gerais, for statistical assistance. Technical assistance by Afonso da Costa Viana/ICB/UFMG, for the biological assays, is fully acknowledged.

\section{References and notes}

1. Urbina, J. A.; Docampo, R. Trends Parasitol. 2003, 19, 495.

2. Coura, J. R.; De Castro, S. L. Mem. Inst. Oswaldo Cruz 2002, 97, 3

3. WHO - World Health Organization, Control of Chagas' Disease; Tech. Rep. Ser. 2002, 905, pp 1-109.

4. Kirchhoff, V. L. In Emerging Infections; Scheld, W. M. et al., Eds.; ASM Press, 1999; pp 111-134.

5. Wendel, S.; Dias, J. C. P. In Chagas' Disease (American Trypanosomiasis): Its Impact On Transfusion and Clinical Medicine Wendel, S., Brener, Z., Camargo, M. E., Rassi, A., Eds.; ISBT Brazil'92-SBHHSch: São Paulo, 1992; p 165 .

6. Chiari, E.; Oliveira, A. B.; Prado, M. A. F.; Alves, R. J.; Galvão, L. M. C.; Araujo, F. G. Antimicrob. Agents Chemother. 1996, 40, 613.

7. Moraes-Souza, H.; Pianetti, G. M.; Pereira-Barreto, C.; Nonoyama, K.; Grogl, M.; Chiari, E. Rev. Soc. Bras. Med. Trop. 2002, 35, 563.

8. Filardi, L. S.; Brener, Z. Mem. Inst. Oswaldo Cruz 1984, 2, 221.

9. Alves, T. M. A.; Chaves, P. P. G.; Santos, L. M. S. T.; Nagem, T. J.; Murta, S. M. F.; Ceravolo, I. P.; Romanha, A. J.; Zani, C. L. Planta Med. 1995, 61, 85.

10. Costa, F. B.; Albuquerque, S.; Vichnevski, W. Planta Med. 1996, 62, 557.

11. Batista, R.; Chiari, E.; Oliveira, A. B. Planta Med. 1999, $65,283$.

12. Leite, J. P. V.; Lombardi, J. A.; Chiari, E.; Oliveira, A. B. Rev. Bras. Farmacogn. 2001, 11, 77.

13. Cunha, W. R.; Martins, C.; Ferreira, D. S.; Crotti, A. E.; Lopes, N. P.; Albuquerque, S. Planta Med. 2003, 69, 470 .

14. Leite, J. P. V.; Oliveira, A. B.; Lombardi, J. A.; Souza Filho, J. D.; Chiari, E. Biol. Pharm. Bull., 2006, in press.

15. Vieira, H. S.; Takahashi, J. A.; Oliveira, A. B.; Chiari, E.; Boaventura, M. A. D. J. Braz. Chem. Soc. 2002, 13, 151.

16. Batista, R.; Braga, F. C.; Oliveira, A. B. Rev. Bras. Farmacogn. 2005, 15, 119.

17. Vieira, H. S.; Takahashi, J. A.; Boaventura, M. A. D. App. Microbiol. Biotechnol. 2000, 53, 601.

18. Lubineau, A.; Gallic, J.; Lemoine, R. J. Chem. Soc. Chem. Commun. 1993, 111, 1419.

19. Roode, B. M.; Franssen, M. C. R.; Van der Padt, A.; Boom, R. M. Biotechnol. Prog. 2003, 19, 1391.

20. Nukada, T.; Berges, A.; Zgierski, M. Z.; Whitefield, D. M. J. Am. Chem. Soc. 1998, 120, 13291. 
21. Chiari, E.; Duarte, D. S.; Raslan, D. S.; Saúde, D. A.; Perry, K. S. P.; Boaventura, M. A. D.; Grandi, T. S. M.; Stehmann, J. R.; Anjos, A. M. G.; Oliveira, A. B. Phytoter. Res. 1996, 10, 636.

22. Faria, T. J.; Silva, L. G. F.; Souza-Filho, J. D.; Chiari, E.; Oliveira, A. B. J. Braz. Chem. Soc. 2005, 16, 1415.
23. Kren, V.; Martinková, L. Curr. Med. Chem. 2001, 8, 1303.

24. Etse, J. T.; Gray, A. I.; Waterman, P. G. J. Nat. Prod. 1987, 50, 979.

25. Iwakura, Y.; Imai, Y.; Yagi, K. J. Polym. Sci., Part A-1: Polym. Chem. 1968, 6, 1625. 